\title{
O processo civil e a reforma constitucional
}

\author{
Luis Eulalio de Bueno Vidigal \\ Catedrático de Direito Juđiciário Civil na \\ Faculdade de Direito da Universidade de \\ São Paulo.
}

1 - Para aquêles dentre vós, que, como eu, fizeram do processo civil o assunto principal de seus estudos, leituras e meditações - e são quase todos os presentes não surpreenderá o tema que escolhi para minha primeira palestra nesta gloriosa terra riograndense. Sabeis, sem dúvida, que a nossa disciplina, depois de ter penetrado audaciosamente no campo do direito privado, reivindicando para o seu âmbito, entre outras matérias, nada menos que a proteção possessória, os ıdireitos reais de garantia, a responsabilidade civil e a falência, volta-se para o direito público, ao qual timbra em pertencer, e aí disputa ao Direito Internacional e ao Direito Administrativo o privilégio de inspirar à Teoria Geral do Direito e do Estado alguns de seus postulados fundamentais.

O nosso grande Couture, que, ùltimamente, se projetara de tal forma no mundo da ciência processual, que deixara de ser apenas uma glória da ciência sul-americana, para integrar-se no firmamento da cultura européia e norte-americana, salientou, ao tratar das garantias constitucionais do processo civil, que grande tarefa, digna de absorver tôda a atenção da doutrina processual moderna, seria o exame dos grandes institutos do Direito Processual à luz do Direito Constitucional.

Não irei aqui desenvolver, segundo a Constituição Brasileira, a bela lição de Couture sôbre o caráter cívico da ação e da exceção. Nem, por igual, insistirei sôbre as 
garantias constitucionais da petição, da defesa, da afirmação e da prova. Lembrarei, apenas, nas palavras preliminares desta oração, secundando o nosso pranteado mestre, que cada um dos institutos do processo civil significa o desenvolvimento de um preceito constitucional. E como nas constituições se encontram as máximas garantias da liberdade individual, é aqui, neste generoso solo do Rio Grande, que se encontra o clima propício para os debates constitucionais. "Tudo nesse belo país" - evoquemos o vosso grande Alcides Lima - "induz o homem a amar a liberdade sem peias".

Aceitai, pois, com benevolência, as críticas de textos constitucionais que vos ofereço. E já que o Rio Grande do Sul tem dado ao país, em tôda a sua história, o mais belo exemplo de ardor cívico e de maturidade para a democracia, permiti que, dos temas processuais do momento, eleja, para esta alocução, os que diretamente dependem da reforma constitucional.

2 - Da indecisão, que nasceu com a república e a federação, a propósito de unidade ou pluralidade processual, e de dualidade ou unidade de justiça, até agora não logramos escapar.

Recorda José Frederico Marques, em magistral aula de abertura de cursos que, a princípio, apesar do Decreto $n .^{\circ}$ 1 , de 15 de Novembro de 1889 , que proclamava a forma republicana federativa e elevava as províncias a estados, o Govêrno Provisório conservou a unidade do Poder Judiciário. $\mathrm{O}$ decreto $\mathrm{n} .^{\circ} 848$, de 11 de Outubro de 1890 antecipando-se a nossa primeira constituição republicana, "organizou de modo autônomo a justiça federal"

Reveladora das tendências de nossos legisladores da época é a parte final de seu artigo 387: "Os estatutos dos povos cultos e especialmente os que regem as relações jurídicas na República dos Estados Unidos da América do Norte, os casos de Common Law e Equity, serão também subsidiários da jurisprudência e processo federal". 
Na ânsia ingênua de hossos republicanos, passávamos bruscamente do regime das Ordenações e da Lei da Bôa Razão, que mandava aplicarem-se, sucessivamente, nos casos omissos, as leis imperiais, as glosas de Accursio e a opinião de Bartolo, para os estatutos dos Estados Unidos da América do Norte, a Common Law e a Equity. Foi essa mesma tendência que levou Leopoldo de Bulhões, na Constituinte, a sustentar que os estados deveriam legislar sôbre o direito material (que a moda de então denominava substantivo), direito processual e organização da justiça. Não tendo prevalecido essa opinião, e nem a que, no extremo oposto, advogava a unidade do direito formal e da justiça, afirma José Frederico Marques que a dualidade judiciária ficou plenamente consagrada na Constituição republicana de 1891. Aceitando inteiramente a sua conclusão, de acêrto indiscutível, temos a impressão de que a Constituição não consagrou claramente nem a dualidade da justiça e nem a pluralidade do processo.

Quanto ao processo, ela era, sôbre o assunto, tão vacilante, que João Mendes Júnior, um dos mais sérios processualistas de São Paulo, ainda em 1918, trinta anos depois de proclamada a república, sustentava a preeminência do Congresso Nacional para sôbre êle legislar.

$\mathrm{O}$ artigo 15 declarava órgãos da soberania nacional o Poder Legislativo, o Executivo e o Judiciário. Todavia, depois de declarar que o Legislativo era exercido pelo Congresso Nacional, o Executivo, pelo Presidente da República, limitava-se, quanto ao Judiciário, a declarar que teria por órgãos o Supremo Tribunal Federal e os juízes e tribunais federais. Omitia, pois, dentre os órgãos do Poder Judiciário, precisamente aquêles que se destinavam a exercer a jurisdição ordinária, isto é, os componentes da Justiça dos Estados.

A reforma constitucional de 1926 manteve o mesmo sistema, corrigindo apenas certos dispositivos de exagerado cunho federativo, como, por exemplo, o item $d$ to artigo 
60, que dava aos juízes e tribunais federais competência para processar e julgar os litígios entre cidadãos de estados diversos.

Na Constituição de 1891, mesmo depois da reforma de 1926, não estava explícito que coubesse aos Estados legislar sôbre direito processual. Esse poder estava, porém, implícito no sistema adotado. O Congresso Nacional tinha poderes para legislar privativamente sôbre o direito processual apenas da justiça federal. Dessa limitação e da declaração de que aos Estados cabia todo e qualquer poder ou direito que lhes não fôsse, explícita ou implicitamente, negado pela Constituição, resultava a sua faculdade de legislar sôbre direito processual.

Quanto à Justiça dos Estados, igualmente, não havia texto expresso, de que claramente resultasse que, como órgão da soberania nacional, exerceria uma das funções em que ela se desdobrava. Por falta de experiência da prática federativa, supôs-se que o Poder Judiciário dos Estados deveria ser regulado pelas constituições dêstes, tal como devia ocorrer com o Legislativo e o Executivo. Não se atentou devidamente em que êstes dois poderes tinham suas atribuições limitadas às matérias da órbita federal, cabendo aos correspondentes estaduais as respectivas funções nas matérias da competência dos Estados, ao passo que ao Poder Judiciário dos Estados deveria caber a aplicação de tôda a legislação brasileira, federal, estadual ou municipal.

3 - Na Constituinte de 1934, o problema, embora sentido, permaneceu sem solução. A experiência do primeiro periodo republicano evidenciara que difícilmente se poderia conciliar o regime da pluralidade processual com a existência, impossivel de negar-se, de órgãos soberanos das justiças estaduais. Pouco propensos a reconhecer essa incompatibilidade, ilustres juristas, constituintes de 1934, debateram-se, inùtilmente, entre contradições, avanços $\mathrm{e}$ 
recuos, que se espelharam no texto da Constituição, tão imperfeito quanto o de 1891, sem as excusas da falta de experiência republicana e federativa.

4 - Reconheçamos que, a êsse tempo, não era fácil encontrar o caminho doutrinário para a harmonização dos processos e, sobretudo, das justiças estaduais e federal.

Nicola Jaeger fêz recentemente brilhante investigação a respeito da repartição dos poderes jurisdicionais no estado federal. Para vergonha nossa, não foi na América, e sim na Itália, de gloriosa tradição científica, que apareceu o conceito de jurisdição indireta, a que se propôs uma designação nova: autocrinia.

Ao poder de formar normas jurídicas válidas e eficazes com relação a determinado ordenamento jurídico escreve Jaeger - "reconhecido a sujeito diferente da instituição soberana e que, portanto, não se pode considerar como exercício de soberania, deu a doutrina mais acreditada o nome de autonomia. Ao poder de administrar, desenvolvida no interêsse da coletividade política por órgãos de entidades distintas do Estado, o nome de autarquia. Se admitirmos, ao lado dessas duas figuras de legislação e administração indiretas, ainda uma terceira, correspondente à terceira função estatal, de jurisdição indireta, poder-se-ia adotar, para designá-la, o nome, formado, :segundo as mesmas regras semânticas, de autocrinia".

5 - Salienta Jaeger, com tôda a procedência, e a história o confirma, que nenhuma razão lógica existe para afirmar-se que a jurisdição seja uma função exclusiva do Estado. Tanto assim é, que a doutrina moderna, sem enfrentar o problema do monopólio estatal da jurisdição, tem proposto, para certas atividades não pròpriamente jurisdicionais, nomes diversos, tais como, substitutivos do juízo público (sugerida por Lessona) ou equivalentes jurisdicionais (sugerida por Carnelutti). 
6 - A autocrinia - prossegue Jaeger — é o poder reconhecido por um ordenamento jurídico, a órgãos pertencentes a outra instituição, de emitir provimentos jurisdicionais eficazes. Na mesma medida em que o Estado outorga a êsses órgãos uma parcela de seu poder jurisdicional, perde correspondentemente igual parcela de seu próprio poder. Do ponto de vista lógico, portanto, não há razão para admitir-se que o Estado se reserve o poder supremo de rever e reformar os provimentos jurisdicionais emitidos pelos órgãos delegados.

A determinação dos casos em que se pode divisar causa suficiente para a admissão das formas da jurisdição indireta, tende a coincidir com as linhas dentro das quais se admite o poder de disciplinar as relações jurídicas substanciais: sempre que o ordenamento estatal consente que vontades diversas da vontade dos órgãos públicos ditem ordens vinculantes, sob a forma de normas ou de ordens concretas, aí também não veda que aquelas mesmas vontades disponham também a respeito do modo de resolver os correspondentes conflitos. Em outras palavras: a extensão da autocrinia coincide com a da autonomia. E se, perante a lei, não se verifica absoluta coincidência e sim, apenas, uma tendência para essa coincidência, isso se deve sòmente ao desconhecimento dessa doutrina por parte do legislador.

7 - É difícil prognosticar o destino que terá a engenhosa sugestão de Jaeger. Seja como fôr, é bem provável que não houvessem os nossos legisladores, especialmente os constituintes, tateado durante tanto tempo se a tivessem tido a orientá-los em seus trabalhos.

Em primeiro lugar, não teriam permitido que, por falta de clareza no sistema, se instituísse a justiça local como titular da jurisdição ordinária e a federal como jurisdição de exceção. As jurisdições não estatais, que pululavam na Europa, antes da Revolução Francesa, já estavam, no Brasil, extintas desde 1824, isto é, desde a nossa 
Constituição Imperial. Portanto, imbuídos da noção, já então corrente, do monopólio da jurisdição pelo Estado, só se pode explicar o prevalecimento da jurisdição estadual pela idéia, que talvez tenha estado no espírito de nossos constituintes - e que não vingou - de que o Brasil era uma união de estados soberanos.

Depois, já teriam sido, de há muito, delimitados e precisados os casos de revisão das decisões locais pelo Supremo Tribunal Federal, problema que há tanto tempo vem desafiando a argúcia dos nossos legisladores, e que se renova, cada dia com mais gravidade, à medida que se torna mais agudo o congestionamento de feitos no Supremo.

8 - A unidade da justiça e a unidade do processo no estado federal são problemas que estão constantemente a se entrelaçar. Aqui do Rio Grande do Sul partiu, há pouco, a mais viva repulsa a um projeto de emenda constitucional, que intentava introduzir, no Brasil, a unificação da Justiça.

A manifestação de vosso Tribunal de Justiça contra êsse malsinado plano - reproduzo, agora, palavras proferidas em São Paulo por José Frederico Marques - "foi feita em admirável peça de doutrina jurídica e de defesa das prerrogativas dos estados, trabalho digno de ser lido pela linguagem corajosa com que o sadio autonomismo dos pampas extravasou seu candente e patriótico repúdio à empreitada unitarista."

Difìcilmente se encontrará um jurista de São Paulo ou do Rio Grande do Sul, que aceite a unificação da justiça. Reconheçamos, porém, que o regime ideal da supremacia ou da exclusividade da justiça local até agora não foi instituído com o cuidado de pormenores que exige para sua perfeita aplicação.

O Congresso Jurídico Americano, de 1900, assentara a conveniência da unidade do processo. No Congresso Judiciário de 1908, Levi Carneiro, convencido dessa tese, 
e igualmente convencido de que a Constituição a repelia;. propôs que se realizasse a unidade do processo por obra. doutrinária, pela aceitação, por parte dos Estados, da lei processual que o Congresso Nacional adotasse. Em 1934, na Constituinte, propôs se atribuisse à União a competência para elaborar as normas fundamentais do processo, facultando-se aos Estados legislarem, sôbre a matéria; paralela, complementar e subsidiàriamente. A idéia de Levi Carneiro não triunfou. Reservou-se à União a facul-dade de legislar sôbre direito processual, mas não se deư aos Estados a de, a respeito, legislar subsidiàriamente: Salientara Levi Carneiro, em discurso, lembrando advertência de Philadelpho Azevedo, que o importante era inda-gar e resolver se o processo se liga mais ao direito substantivo ou à organização judiciária. Entenderam os constituintes de 34 que o processo se ligava mais ao direitơ substantivo e, simplisticamente, permitiram aos Estados legislar sôbre sua divisão e organização judiciária.

9 - A Constituição de 1937 manteve a unidade processual, ressalvando aos Estados o poder de legislar para suprir as deficiências da lei federal ou atender às peculiaridades locais. A Constituição de 1946 voltou ao sistema de 1934.

10 - Vejamos, agora, alguns problemas que o texto da Constituição deixa sem solução.

o Código de Processo Civil Brasileiro e algumas leis processuais federais declararam taxativamente quais os recursos admissíveis. Não há, porém, texto constitucionaI que obrigue os Estados a terem determinados órgãos judiciários. Ao contrário, de um lado, declara a Constituição que aos Estados se reservam todos os poderes que, implicita ou explìcitamente, não lhes sejam por ela vedados; de outro lado, dispõe minuciosamente sôbre a justiça dos Estados sem obrigá-los a criar órgãos judiciários; que algumas leis federais pressupõem. 
A Constituição só se refere expressamente a juizes de primeira instância e um ou vários tribunais de apelação. Nenhuma dúvida ou dificuldade para o processo e o julgamento das apelações.

O mesmo não acontece com os demais recursos.

11 - Os embargos infringentes, que o Código de Processo, com dupla imprecisão, chama "de nulidade ou infringentes do julgado" poderão, conforme a lei de organização judiciária, constituir autêntica terceira instância, como ocorre no Estado de São Paulo, ou conservar a sua pureza tradicional de oposição feita à sentença perante o mesmo juiz que a proferiu.

12 - $\mathrm{O}$ agravo de petição, que a lei n. ${ }^{\circ} 1.533$ estabeleceu como recurso ordinário contra a sentença definitiva de mérito proferida em mandado de segurança, não tem, perante a legislação paulista, possibilidade de processar-se em certos casos.

A lei paulista n. $^{\circ}$ 2.554, de 14 de Janeiro de 1954, atribui ao Tribunal de Justiça, na plenitude de sua composição, competência para processar e julgar originàriamente os mandados de segurança impetrados contra ato do próprio Tribunal, de suas secções, do Conselho Superior da Magistratura, do Presidente do Tribunal e do Corregedor Geral da Justiça. Uma lei recente, de n. 4.589 , de 3 de Janeiro de 1958, retirou do Tribunal Pleno, e outorgou às suas câmaras isoladas, a competência para processar e julgar os mandados de segurança contra atos do Governador do Estado, da Mesa ou da Presidência da Assembléia Legislativa e do Procurador Geral da Justiça.

Pergunta-se: nos casos de competência originária do 'Tribunal Pleno, qual o Tribunal que deverá conhecer do agravo de petição? Se admitirmos que seja o Supremo Tribunal Federal (o que é muito discutível, porque o Supremo não pode ter atribuições outras que as resultantes de texto expresso da Constituição), como processar o 
recurso? Quem sustentará a decisão agravada? Será possível ao Tribunal local reformar a decisão ao invés de sustentá-la? E se não admitirmos, diante dessas dificuldades, o agravo de petição, será válida uma lei estadual de organização judiciária, que torna impossível a aplicação de uma lei federal?

13 - Sabeis que, no Distrito Federal, logo depois de entrar em vigor o Código de Processo Civil Brasileiro, uma Jei federal introduziu ali a reclamação ao Conselho de Justiça, sucedâneo do antigo agravo com fundamento em dano irreparável, com cuja supressão os advogados locais não se conformaram.

Em São Paulo, por lei estadual, instituiu-se recurso idêntico, a que, eufêmicamente, se denominou correição parcial.

Êste e aquêle têm tôdas as características dos recursos. Podem os Estados criar recursos não previstos no Código de Processc?

14 - Nos Estados em que, em segunda instância, as causas não se distribuem por câmaras ou turmas, não haverá recurso de revista. Sem dúvida, destinando-se êsse recurso à uniformização local da jurisprudência, torna-se desnecessário onde houver um só tribunal de justiça funcionando sempre na plenitude de sua composição. Deverá, porém, admitir-se que o recurso se admita, ou não, segundo as disposições da legislação local?

15 - Quê conclusão tirar do expôsto? A de que os constituintes de 1891, 1934, 1937 e 1946 não atentaram em que a matéria de organização judiciária também é de direito processual e, portanto, a respectiva legislação não pode ficar entregue aos Estados.

O texto constitucional deverá, a nosso ver, dar à União o poder de legislar sôbre direito processual, inclusive normas gerais de organização judiciária. Deve dar aos Estados o poder de legislar sôbre direito processual nas 
omissões da lei federal e, ainda, subsidiária e complementarmente, enquanto a União se abstiver de regular determinadas matérias.

16 - 0 artigo 36 contém uma dessas fórmulas sonoras e vazias em que às vêzes se comprazem os nossos legisladores: "São poderes da União o Legislativo, o Executivo e o Judiciário, independentes e harmônicos entre si.

Nẩo são independentes, pois que os juízes são nomeados pelo Presidente da República ou pelos Governadores dos Estados. Não são harmônicos, pois o Judiciário julga em definitivo os atos do Executivo e do Legislativo. Finalmente, não são os únicos poderes da União, pois também o é o Tribunal de Contas, que, não estando sujeito a qualquer dos outros poderes, pode recusar soberanamente o registro de ato de que resulte obrigação de pagamento pelo Tesouro Nacional.

Inexpressiva e inexata é a fórmula do artigo 36, mas, talvez, inofensiva. Não assim, o $\S 20^{\circ}$ dêsse artigo. $\mathrm{Na}$ proibição, que êle prescreve, de qualquer dos poderes delegar suas atribuições, talvez se encontre explicação da reconhecida e notória ineficiência do Congresso, na elaboração das medidas legislativas, em geral, e dos planos econômicos e financeiros da administração, em particular. Há matérias em que é de todo desaconselhável a publicidade inevitável em todos os trabalhos do Congresso Nacional. Como guardar o segrêdo necessário, em matéria financeira, ou em matéria cambial, para evitar especulações, senão deferindo ao Executivo a incumbência de legislar? Estabeleçam-se garantias e precauções contra os abusos, se quiserem. Subordine-se a delegação a prévia e genérica autorização do Congresso. Limite-se a matéria que the constituirá objeto. Imponha-se o referendum parlamentar até plebiscitário. Não se prive, porém, a Nação, da possibilidade de prover, com reserva, a salvo das especulações e da obstrução parlamentar, a respeito de medidas prementes de Govêrno. 
17 - Os dois capítulos que tratam do Poder Judiciário, o quarto do título I e o título II, apresentam técnica constitucional tão defeituosa, que é de pasmar não tenham sido modificados nestes doze anos.

Já, há pouco, aludimos à origem dessa defeituosa sistematização. Os constituintes de 1891, não afeitos à prática federativa, não atentaram, ao distribuir as competências judiciárias federal e estadual, que ambas constituiam justiça nacional, como bem esclareceu João Mendes Júnior, em sua famosa polêmica com Pedro Lessa. Por isso, a nossa primeira constituição republicana apresenta-se insegura, aludindo ao Poder Judiciário da União e às decisões das justiças dos Estados.

Em 1946, decorridos nove anos de extinção da justiça federal, não poderiam mais subsistir essas vacilações. Entretanto, o que nos depara a Constituição vigente é muito mais grave. No artigo 94, declara singelamente exercer-se o Poder Judiciário pelos seguintes órgãos:

$$
\begin{aligned}
& \text { I - Supremo Tribunal Federal; } \\
& \text { II - Tribunal Federal de Recursos; } \\
& \text { III - Juizes e Tribunais Militares; } \\
& \text { IV - Juízes e Tribunais Eleitorais; } \\
& \text { V - Juizes e Tribunais do Trabalho. }
\end{aligned}
$$

Omite, pois, nada menos que os juizes e tribunais dos Estados, que exercem a jurisdição ordinária cível, e os tribunais do juri, que exercem a jurisdição ordinária criminal, no julgamento dos crimes dolosos contra a vida.

É certo que o Título I dispõe sôbre a Justiça dos Estados. Não o faz, porém, para declarar ou esclarecer que lhe cabe a plenitude da jurisdição ordinária cível e criminal, e sim tão sòmente para estabelecer normas rígidas de provimento e promoção. De sorte que, se algum jurista estranho ao nosso país, tentar, pela leitura da Constituição, descobrir a quem cabe o exercício do poder jurisdicional, estamos em que não o conseguirá. E surpreende-me que 
até agora o espírito fértil, o gênio inventivo e a poderosa imaginação dos advogados não tenham levado às extremas consequências as suas investigações críticas, para negar, pelos seus fundamentos, tôda a competência das autoridades judiciárias estaduais.

18 - A Constituição deu à Justiça do Trabalho competência para julgar dissídios coletivos entre empregados e empregadores e determinou que o legislador ordinário especificasse os casos em que as decisões, nos dissídios coletivos, poderiam estabelecer normas e condições de trabalho.

Tendes presente, sem dúvida, a maneira pela qual tem sido cumprido êsse preceito constitucional. A lei ordinária não cerceou absolutamente o poder normativo da Justiça do Trabalho. O que vemos, em consequência, há mais de dez anos, é os Tribunais do Trabalho aumentarem anual, regular e uniformemente, os salários dos empregados.

Neste, como em inúmeros outros setores, percebe-se o vazio da declaração constitucional da harmonia entre os três poderes da soberania nacional.

Há cêrca de quinze anos o fantasma da inflação vem trazendo o pânico aos que vivem de renda fixa e constituindo preocupação e ponto capital de programas de govêrno. Políticos, banqueiros, economistas e leigos, tornaram-se, mercê das circunstâncias, especialistas em matéria de moeda. Ninguém ignora que uma das mais importantes medidas não monetárias para combater a inflação é o congelamento de preços e salários. De que maneira pode o Govêrno traçar rumos nessa matéria, e procurar segui-los, se outros órgãos do Estado, colocados em plano diverso, anulam, com suas decisões, os planos mais ousados e eficientes para sanear a moeda?

A Constituição deveria estabelecer normas gerais de coordenação entre as autoridades responsáveis pela política da moeda e do crédito e os órgãos jurisdicionais trabalhistas. 
19 - O título II da Constituição adota normas de extrema rigidez, em que se devem conter os Estados ao organizarem a sua justiça:

I - inalterabilidade da divisão e da organização judiciárias, dentro de cinco anos da data da lei que as estabelecer, salvo proposta motivada do Tribunal de Iustiça;

II - possibilidade de criação de tribunais de alçada inferior à dos tribunais de justiça;

III - obrigatoriedade de concurso de provas para o ingresso na magistratura, nos moldes que indica;

Iv - condições de promoção na carreira, obrigatòmente dividida em entrâncias;

$\mathrm{v}$ - composição dos tribunais;

vi - vencimento dos desembargadores e dos demais juízes;

vII - possibilidade de instituição da justiça de paz temporária;

viI - possibilidade da criação de cargos de juízes togados com investidura limitada a certo tempo e competência para julgamento de causas de pequeno valor.

Apesar de pormenorizadas, essas condições estão bem longe de satisfazerem aos requisitos que deve preencher a justiça. O resultado da prática dêsse título constitucional, no Estado de São Paulo, foi desastroso. Os juízes da Capital, na primeira e na segunda instância, estão esmagados pelo serviço, enquanto os do Interior, por falta de exercício, estiolam-se e perdem, pouco a pouco, a capacidade revelada no início da carreira; a perspectiva do estágio no Interior apavora os candidatos à magistratura, ocorrendo, com frequência, vagas para que se não apresentam inscrições; os magistrados habituados à vida pacata do Interior, quando vêm para a Capital, não conseguem, no acúmulo dos serviços forenses, dar estrito cumprimento às disposições dos Códigos de Processo Civil e de Processo Penal. 
As normas de organização judiciária, que a Constituição deve, como sustentamos, prescrever aos Estados, não podem apresentar-se com a rigidez em que as circunscreveu o texto constitucional. $\quad$ preciso dar aos Estados a possibilidade de atenderem às suas peculiaridades.

No Estado de São Paulo, parece-me que seria de tôda a vantagem constituirem polícia, ministério público e magistratura uma só carreira, com as mesmas restrições e prerrogativas. A Constituição deveria permitir aos Estados processos e jurisdições especiais para causas cíveis de baixo valor e criminais de pequena gravidade.

20 - A lei não poderá excluir da apreciação do Poder Judiciário qualquer lesão de direito individual. Disposição fecunda de consequências mas, infelizmente, incompleta. O texto permite ao legislador ordinário excluir da apreciação jurisdicional as simples declarações de direitos. $\mathrm{O}$ artigo 141, $\S 4 .^{\circ}$, deve ser completado: "nem impedir a mera declaração jurisdicional de direitos e obrigações".

21 - O parágrafo 16 do artigo 141 também precisa ser completado. Não basta garantir o direito de propriedade, salvo o caso de desapropriação por necessidade ou utilidade pública. É preciso acrescentar: "quando a lei fixar normas para o processo de desapropriação, deverá ressalvar ao expropriado o direito de, por via ordinária, pleitear ampla e irrestrita indenização".

22 - 0 mandado de segurança foì definido em têrmos tão impróprios que o Brasil inteiro, de norte a sul, passou a adotá-lo não apenas para proteger o particular contra as autoridades administrativas, mas também contra as autoridades judiciárias, convertendo-se em panacéia destinada a resolver tôdas as pendências, haja, ou não, interêsse da administração. Não nos cansaremos de repetir: a Constituição vigente, consagrando o mandado de segurança, não quis subverter todo o nosso sistema processual, 
nem apagar, de um lance, tôdas as lentas conquistas da ciência e da legislação nesse terreno. A nosso ver, a garantia deveria ser assim enunciada: "Salvo para cobrança de tributos e para restringir o uso da propriedade particular ou dela dispôr, a administração executará suas próprias decisões. Todavia, os atos administrativos poderão ter suspensa a sua execução, mediante mandado judicial de segurança, sempre que se revestirem de ilegalidade ou abuso de poder evidentes".

Essa fórmula será, talvez, cerceadora da garantia. Mas essa limitação é necessária. Regozijemo-nos com o instituto, oriundo de nobres pregações e brilhantes lutas forenses. Não suponhamos todavia, que êle possa, e não pretendamos que deva, substituir as ações tradicionais do nosso direito. Para honra nossa, já de há muito a jurisprudência, e agora a própria Constituição, firmaram o princípio da supremacia do Judiciário para a apreciação de qualquer lesão de direito individual. Não incorramos, por inadvertência, na candura, que a nossa condição de juristas repele, de supôr que, alargando o campo de incidência do mandado e simplificando-lhe as formas processuais, estaremos progredindo na senda da liberdade.

23 - Chiovenda, em uma de suas passagens mais eloquentes, criticou vivamente aquêles que não sòmente consideram as formas processuais como um mal, mas ainda, nem sequer lhe concedem a qualificação atenuante de mal necessário. E lembrando Jhering, proclamou que os povos que professam o verdadeiro culto da liberdade, sentem instintivamente o valor das formas, que dela constituem a máxima garantia.

Essa evocação do grande iniciador da corrente de estudos processuais, que ora nos congrega nesta magnífica cidade, traz-me a feliz oportunidade de encerrar estas palavras com uma saudação ao glorioso povo do Rio Grande do Sul. 
Em nenhuma parte, em nosso país, se lutou tanto pelo Brasil. Gerações e gerações de rio-grandenses foram ceifadas nas lụtas do século 18 e em vossa nunca assás glorificada revolução farroupilha, tantas vêzes mal interpretada e detraída, e que, por isso mesmo, tanto comove a nós paulistas e tanto de vós nos aproxima. Honrando, como fazeis, a "Semana de Estudos de Direito Processual", pela presença e pela colaboração que the dão os mais altos representantes do fôro, da cátedra e do pretório, confirmais, talvez inconscientemente, a observação daqueles dois grandes mestres. Quem cultiva o direito processual, e lhe respeita as formas, honra e cultúa a liberdade. Do Rio Grande do Sul, que sempre foi mestre de democracia e de civismo, não poderia deixar de partir o toque de reunir dos especialistas de todo o Brasil. Que êle seja o prenúncio das grandes realizações que auguramos para todos os nossos processualistas, afim de que venha o Brasil a ocupar, na América, na ciência do Direito Processual, a mesma gloriosa posição que lhe conquistaram os nossos grandes civilistas do século passado. 